\title{
Impacto da pandemia de Covid-19ao sistema social e sells subsistemas: reflexões a partir da teoria social de Niklas Luhmann
}

\section{Léo Peixoto Rodrigues* ${ }^{*}$ Everton Garcia da Costa* ${ }^{* *}$}

\section{Resumo}

Este artigo tem como objetivo tecer algumas reflexões, a partir de uma abordagem sociológica, acerca do impacto da pandemia de Covid-19 sobre o funcionamento dos sistemas e subsistemas sociais. Para levar a cabo esta proposta, nos ancoramos nos pressupostos teórico-epistemológicos da teoria social desenvolvida pelo sociólogo alemão Niklas Luhmann, principal expoente do pensamento sistêmico nas Ciências Sociais. Defendemos o argumento de que a pandemia do novo coronavírus causa uma perturbação sistêmica que impacta profundamente o funcionamento de toda a sociedade global, bem como, por seus sistemas e subsistemas sociais, impõe uma série de desafios à reprodução da vida social.

Palavras-chave: Covid-19, sociedade, sistemas sociais, Luhmann.

\footnotetext{
* Universidade Federal de Pelotas, Pelotas, RS, Brasil.

** Instituto Federal de Educação, Ciência e Tecnologia Sul-rio-grandense (IFSul), Pelotas, RS, Brasil.
} 


\section{Impact of the Covid-19 pandemic on the social system and its subsystems: reflections from Niklas Luhmann's social theory}

\section{Abstract}

This article aims to make some reflections, based on a sociological approach, about the impact of the Covid-19 pandemic on the functioning of social systems and subsystems. To this end, we draw on the theoretical-epistemological assumptions of the theory of society developed by the German sociologist Niklas Luhmann, the main representative of systemic thinking in the Social Sciences. We argue that the new coronavirus pandemic causes a systemic disturbance that has a profound impact on the functioning of the entire global society, as well as on its social systems and subsystems, imposing a series of challenges on the reproduction of social life. Keywords: Covid-19, society, social systems, Luhmann.

\section{Introdução}

m dezembro de 2019, a China comunicou à Organização Mundial
da Saúde (OMS) a descoberta de uma nova doença causada por
um tipo de coronavírus que causa síndromes respiratórias graves em humanos. No início, a doença foi claramente subestimada pelos governos e autoridades internacionais de saúde. Em janeiro, o governo chinês afirmou que o vírus recém-descoberto apresentava baixo risco aos humanos - muito embora tenha ordenado o isolamento completo da cidade de Wuhan, onde a doença teria surgido. A OMS, por sua vez, à época, afirmou ser cedo para falar em uma emergência de saúde pública, elevando a situação para o status de pandemia apenas no dia 9 março daquele ano. Poucos dias depois, ainda neste mês, o novo coronavírus mostrava ao mundo a sua gravidade, colapsando o sistema de saúde italiano, levando centenas de pessoas a óbito a cada dia. Até o momento em que este artigo foi finalizado (março 
de 2021), a Covid-19 já contaminou mais de 117 milhões de pessoas no planeta, levando 2,6 milhões a óbito - 266 mil apenas no Brasil. ${ }^{1}$

Diante da gravidade dessa crise sanitária global, o objetivo deste artigo é apresentar uma proposta de reflexão acerca da pandemia de Covid-19, à luz da teoria dos sistemas sociais luhmanniana. Mais precisamente, o intuito consiste em apresentar as vantagens desse modelo teórico para a compreensão dos impactos da pandemia sobre o funcionamento dos sistemas sociais, estabelecendo o terreno para o desenvolvimento de uma agenda de pesquisas futuras.

Além desta introdução, o texto está dividido em outros três momentos: primeiro, fazemos uma breve apresentação de algumas das principais noções do vasto arcabouço conceitual luhmanniano; na sequência, são estabelecidos os elementos teóricos que nos permitem construir uma reflexão sociológica a respeito dos impactos da pandemia sobre o funcionamento dos sistemas e subsistemas sociais; finalmente, à luz desses elementos, procuramos demonstrar como o dito modelo teórico pode ser aplicado na análise do impacto empírico da crise pandêmica sobre os sistemas e subsistemas da sociedade.

\section{A sociedade pela ótica sistêmica}

O objetivo desta seção é tecer algumas reflexões acerca dos principais pressupostos teóricos e epistemológicos relacionados à teoria dos sistemas

\footnotetext{
${ }^{1}$ Consideramos importante ressaltar aqui que este artigo começou a ser escrito logo no começo da pandemia, mais precisamente, em março de 2020. Aquele era ainda um momento de muitas incertezas quanto aos rumos da pandemia no mundo e no Brasil (o número de óbitos no planeta era de 700 mil, enquanto hoje já passa de 2,6 milhões). Não sabíamos, por exemplo, quando teríamos acesso a uma vacina e tampouco sobre o impacto real da pandemia nos países mais pobres, posto que era o instante em que as primeiras medidas de distanciamento social começavam a ser adotadas. No decorrer de 2020, como sabemos, a pandemia tomou contornos dramáticos, não apenas no que diz respeito ao número oficial de óbitos e de infecções, mas também no impacto causado às economias nacionais pelo distanciamento social. De lá para cá, surgiram novas ondas de contaminação, descobriram-se novas cepas do Sars-Cov-2 e teve início a vacinação. Com efeito, ao longo processo de avaliação e edição deste manuscrito, os dados apresentados tiveram de ser atualizados - mais de uma vez - antes da publicação do artigo. No entanto, frisamos que as ideias que sustentam a argumentação foram germinadas "no olho do furacão", isto é, no princípio da pandemia de Covid-19.
} 
sociais desenvolvida pelo sociólogo alemão Niklas Luhmann. Não se trata, no entanto, de descrever pormenorizadamente o vasto arcabouço conceitual luhmanniano, algo que já fizemos em outros trabalhos (Rodrigues; Neves, 2012; 2017; Rodrigues, 2008; Costa, 2018). Antes disso, o intuito aqui é tão somente apresentar o modo como a sociedade moderna é vista à luz do pensamento teórico do referido autor para, ao fim e ao cabo, demonstrar empiricamente, através de dados secundários até então disponíveis, o impacto que a pandemia vem causando aos diferentes sistemas e subsistemas sociais, sobretudo se for levado em conta o distanciamento social imposto pela Covid-19.

O modelo teórico desenvolvido por Luhmann (1997; 1998; 2006) é uma teoria da diferença, mais precisamente, um modelo explicativo que procura investigar sociologicamente a diferença que existe entre sistema e entorno. Por sistema, entenda-se toda unidade que consegue se (auto)diferenciar do ambiente (entorno) no qual está inserida, mantendo um determinando padrão de funcionamento. $\mathrm{O}$ pensamento sistêmico possui uma larga tradição nas ciências sociais, começando com o trabalho pioneiro de Pareto, Tratado de sociologia geral, publicado em 1916, avançando com a obra de Parsons, O sistema social, em 1951, até a publicação da obra paradigmática de Luhmann, Sistemas sociais: esboço de uma teoria geral, em 1984. ${ }^{2}$ Vale destacar aqui que Luhmann dedicou toda a sua carreira acadêmica como professor da Universidade de Bielefeld à construção de um modelo sociológico cujas ferramentas conceituais the permitissem observar e explicar o funcionamento da sociedade moderna, concebida como um entremeado de sistemas e subsistemas ${ }^{3}$ de comunicação. A importância de Sistemas sociais está no giro epistemológico empregado pelo autor ao pensamento sistêmico social, a partir da apropriação do conceito de autopoiésis desenvolvido na segunda metade do século XX pelos biólogos chilenos Humberto Maturana e Francisco Varela.

2 Para o conhecimento de aspectos da reconstrução dessa história, ver Rodrigues $(2013 ; 2014)$.

${ }^{3}$ Os subsistemas devem ser observados como "ambientes" dos sistemas sociais, isto é, como "sistemas parciais", diferenciações funcionais que os sistemas fazem ao longo de seu processo evolutivo. A ciência moderna, por exemplo, encontra-se diferenciada em um incontável número de disciplinas que operam como subsistemas: química, física, biologia, sociologia etc. Apesar de estarem inseridos num "sistema mais amplo", os subsistemas possuem sua própria autopoiése, atuando como entorno para o sistema do qual fazem parte. 
Maturana e Varela caracterizam como sistema autopoiético aquele capaz de produzir, ele próprio, os elementos pelos quais é constituído, bem como de auto-organizar a rede de conexões internas entre esses elementos, num contexto de contínuas perturbações (ruídos) do meio (Maturana, 1987; Maturana; Varela, 1998). Sistemas autopoiéticos, defendem os autores, são um tipo especial de sistema operacionalmente fechado - isso significa dizer que eles nunca interagem diretamente com o entorno (ou ambiente), mas somente através de "irritações". ${ }^{4} \mathrm{O}$ fechamento operacional permite ao sistema ter autonomia para ignorar determinadas perturbações (comunicações) e rechaçar outras. Há perturbações, no entanto, que, dada a sua magnitude, não podem ser simplesmente ignoradas ou rechaçadas. Muitas delas geram irritações que levam o sistema a se reorganizar internamente, no sentido de compensar (responder) os ruídos do entorno. Além disso, há ainda perturbações que, de tão severas, podem levar ao colapso (morte) do sistema. Conforme Maturana (1997) e Maturana e Varela (1998), os organismos vivos são sistemas autopoiéticos e é dessa forma que eles interagem com o seu ambiente, ou seja, através de perturbações/ compensação de perturbações. ${ }^{5}$

Luhmann (1998) dá novos rumos à teoria dos sistemas sociais ao se apropriar dessa noção criada no seio da biologia. Em sua abordagem, existem pelo menos três tipos de sistema com características autopoiéticas: organismos vivos, sistemas psíquicos e sistemas da sociedade. É importante ter em mente, nesse contexto, que no escopo da teoria luhmanniana a sociedade não é constituída por indivíduos, como tradicionalmente ocorre

\footnotetext{
4 Termo técnico utilizado para a própria descrição de sistema autopoiético, e como ele se "relaciona com o ambiente", proposto por Maturana e Varela (1980).

${ }^{5}$ Do ponto de vista puramente biológico, segundo a teoria de Maturana e Varela (1998), um sistema auto-organizável/autopoiético é aquele que, não obstante necessita de um meio para se acoplar, consegue reconhecer este meio, adaptar-se a ele e assimilar as suas modificações, respondendo através da emergência (sempre a partir de seus próprios elementos) de novos estados de ordem os quais visam à sua perpetuação. Um vírus, suas infecções - utiliza células como hospedeiros, através de mecanismos de acoplamento estrutural - e suas mutações como auto-organizáveis é um adequado exemplo de sistema orgânico autopoiético. A teoria dos sistemas sociais autopoiética identificou essa mesma lógica em outros sistemas, tais como o psíquico e o social (Luhmann, 1998; 2006; 2016).
} 
nas ciências sociais. Para Luhmann, a sociedade é constituída unicamente por comunicações e tudo aquilo que não o for deve ser observado como ambiente $^{6}$ - os indivíduos, como sistemas psíquicos, constituiriam o entorno (ambiente) dos sistemas sociais. Por comunicação, o pensador alemão compreende um acontecimento emergente e improvável que se concretiza através da composição de três seleções: a) seleção do ato de comunicar; b) seleção da informação a ser comunicada; e c) seleção que ocorre no ato de entender (ou não) a informação e o ato de comunicar. Segundo Luhmann (2009; 2001), nenhum desses elementos, de forma isolada, pode constituir a comunicação, a qual só ocorre mediante sua síntese. Sobre isso, Rodrigues e Neves argumentam que a

comunicação é a operação própria dos sistemas sociais. É uma operação puramente social porque pressupõe o envolvimento de vários sistemas psíquicos sem que se possa atribuí-la exclusivamente a um ou outro desses sistemas: não pode haver comunicação individual. A comunicação cumpre, ademais, os requisitos da autopoiésis, ou seja, unidade, limite e capacidade de relacionar operações posteriores a partir de anteriores, ou seja, depende de si mesma para prosseguir. Com isso, Luhmann consegue indicar um unit act que caracterize os sistemas sociais, um ponto arquimédico para a observação do social, sem precisar recorrer a qualquer outro elemento ad hoc (Rodrigues; Neves, 2017, p. 90-91).

Com este argumento teórico, ou seja, ao defender que tudo aquilo que não é comunicação tem de ser visto como ambiente, Luhmann (1997a) desloca o ser humano, como foi mencionado, do centro para o entorno da sociedade. As comunicações, certamente, emergem a partir da interação (comunicativa) entre os indivíduos (sistemas psíquicos), no entanto, elas não podem ser reduzidas a nenhum deles em específico. E à medida que se conectam umas às outras, tem-se então a formação dos sistemas sociais educação, política, ciência, arte, religião. Como salienta Stichweh (2012), a conectividade sequencial de um incontável número de comunicações leva

${ }^{6}$ É importante ressaltar aqui que as comunicações podem ser também em torno umas das outras. 
aos processos de formação de sistemas. Sob esse prisma teórico, a própria sociedade deve ser observada como um gigantesco sistema que aglutina todas as comunicações possíveis, diferenciando-se funcionalmente em um incontável número de sistemas e subsistemas sociais.

Cada sistema social desempenha uma função específica necessária ao funcionamento da sociedade - necessidade essa surgida no decurso evolutivo $^{7}$ da vida social na era moderna. Nesse contexto, a educação, por exemplo, surge a partir do momento em que a sociedade moderna demandou um sistema específico para lidar com as operações pedagógicas, função que não poderia ser desenvolvida por nenhum outro sistema social, como a economia ou o direito, por exemplo, os quais já possuíam suas próprias funções. Também é preciso ter em mente que os diferentes sistemas sociais possuem sua própria autopoiese, de maneira que tudo aquilo que não é o próprio sistema tem de ser visto como entorno, inclusive os demais sistemas sociais. Além disso, cada um desses sistemas possui seus próprios ambientes internos, que podem ser vistos como sistemas parciais ou subsistemas. Desse modo, o sistema jurídico, por exemplo, está organizado em diferentes áreas: direito civil, penal, trabalhista, empresarial etc. Do mesmo modo, o sistema científico encontra-se diferenciado em um vasto número de disciplinas: química, física, matemática, biologia, sociologia etc. A isto, Luhmann (2006) chamou de "diferenciação funcional".

Os sistemas e subsistemas sociais possuem relativa autonomia para organizar seus processos internos, para compor e decompor seus componentes estruturais, bem como para reorganizar/reestruturar a relação entre esses. Cabe reiterar que tais sistemas nunca interagem diretamente entre si, mas somente através de irritações. Isso não significa dizer, no entanto, que eles operem de forma isolada. Pelo contrário, à medida que as relações sociais se tornaram mais imbricadas e complexas no mundo

${ }^{7}$ Luhmann $(1998 ; 2006$; 2016) ressemantizou e admitiu o termo "evolução" da sociedade, mas de forma complexa e diferente da clássica e reducionista ideia de "darwinismo social", que ainda perdura negativamente em algumas abordagens de teoria sociológica contemporânea. 
globalizado, os sistemas sociais passaram a funcionar cada vez mais acoplados estruturalmente uns aos outros, de modo que o efetivo funcionamento de um sistema depende da operação dos demais que estão ao seu redor. Mudanças estruturais ocorridas dentro de um único sistema social podem gerar uma rede de perturbações sobre outros sistemas, levando-os, muitas vezes, a se reestruturarem numa tentativa de compensar tais ruídos, ou até mesmo de adaptarem-se a tais perturbações desse entorno em que estão acoplados, para manterem-se e não perecerem - exercendo assim a autopoiésis. Isso é bastante comum diante de crises no sistema econômico, por exemplo, ou no sistema político, as quais normalmente afetam todas as dimensões da vida social.

\section{O sistema de saúde no pensamento sistêmico}

Por se tratar de uma teoria universal, dotada de um vasto arcabouço conceitual voltado à análise da complexidade dos fenômenos sociais, a teoria luhmanniana, já há algum tempo, vem sendo utilizada em investigações no campo da saúde (Corsi; Esposito; Baraldi, 1996; Schwartz, 2003; Martini 2015; Rocha; Kòlling; Olsson, 2020). É importante salientar, com efeito, como revela Martini (2015), que Luhmann não tratou do sistema da saúde, mas especificamente do sistema de medicina. Diferentemente dos demais sistemas sociais, o sistema médico não se concentra em si mesmo, mas, antes, no entorno da sociedade, isto é, nos seres humanos, posto que sua tarefa principal é garantir as condições físicas e psicológicas que assegurem a vida humana e, consequentemente, a comunicação, base do sistema da sociedade e de seus sistemas e subsistemas sociais. A finalidade dos profissionais médicos, argumenta Luhmann, consiste em justamente intervir quando um indivíduo se encontra impossibilitado de ser uma base orgânica ou psíquica para a comunicação (Corsi; Esposito; Baraldi, 1996). O sistema médico, com efeito, na abordagem de Luhmann é descrito como um sistema eminentemente curativo, voltado ao tratamento dos doentes. 
Segundo Luhmann $(1998 ; 2006)$, os sistemas sociais operam orientados por um código binário formado por um valor positivo e outro negativo, por exemplo, verdade/não verdade, no caso do sistema científico, e legal/ não legal no caso do sistema jurídico. No que diz respeito ao sistema da medicina, este opera a partir do código saudável/doente (ou são/ enfermo). Os indivíduos doentes são aqueles que apresentam alguma enfermidade ou problema que afeta sua saúde física ou mental, e que, portanto, necessitam de algum tipo de intervenção curativa. Com efeito, na abordagem luhmanniana o sistema da medicina apresenta outra importante particularidade: ele se orienta pelo valor negativo, quer dizer, tem seu foco direcionado à doença. Isso ocorre, defende Luhmann, porque os médicos só entram em ação diante da presença da doença, uma vez que indivíduos saudáveis não precisam ser curados. O olhar da medicina moderna, portanto, não está na saúde, e sim na enfermidade A respeito disso, Rocha, Kòlling e Olsson argumentam que

o foco do sistema médico está na atuação dos médicos, com a pretensão de selecionar a intervenção apropriada sobre o corpo doente, por meio de diagnósticos e tratamentos, com o propósito de alcançar um estado de saúde. A função desse sistema está vinculada à vida humana e à saúde para o tratamento de doenças, ou seja, o sistema opera unicamente quando verificada a hipótese de doença, o código negativo do sistema médico. Nesse aspecto, o ambivalente funcional da doença, qual seja, a saúde, não é, em um primeiro momento, o aspecto determinante para o funcionamento do sistema. Por consequência, em tese, não se vislumbra espaço para a integração de ações preventivas no âmbito desse sistema (Rocha; Kòlling; Olsson, 2020, p. 160).

É importante destacar, assim, que a visão de Luhmann sobre o sistema médico não deve ser vista como normativa, longe disso. Conforme argumenta Martini (2015), o que Luhmann fez foi apenas descrever sociologicamente o sistema da medicina moderna da forma como ele se apresentava. Todavia, não se pode perder de vista que o modelo biomédico ocidental, focado exclusivamente no tratamento da enfermidade e na intervenção curativa dos médicos (e que por isso acaba por deixar de lado a atuação de outros 
profissionais da saúde, igualmente relevantes, como os enfermeiros, por exemplo) vem sendo alvo de críticas veementes. Do mesmo modo, a própria ideia de saúde como ausência de enfermidade também vem sendo criticada. A Organização Mundial da Saúde (OMS), por exemplo, desde o final da primeira metade do século passado, trabalha com uma concepção muito mais holística de saúde, entendida como "um estado de completo bem-estar físico, mental e social". No Brasil, desde os anos de 1970-1980, adquiriu destaque o chamado movimento pela Saúde Coletiva, o qual não só parte dessa visão holística e integral de saúde, como também engloba conhecimentos produzidos nas diferentes disciplinas das ciências humanas e sociais, bem como da filosofia (Silva; Schraiber; Mota, 2019).

Consequentemente, em face das limitações da noção de sistema médico desenvolvida de forma muito genérica por Luhmann é que muitos autores do campo do pensamento sistêmico têm procurado desenvolver o conceito de sistema de saúde. Tais autores partem do princípio de que a saúde é um sistema social que "apresenta claramente autorreferência e autopoiese e, assim, diferencia-se do seu ambiente" (Martini, 2015, p. 114). O sistema da saúde consiste numa noção muito complexa, a qual parte de uma definição ampla de saúde, que vai muito além da mera ausência de enfermidade. Do mesmo modo, e justamente por isso, parte também do pressuposto basilar de que a saúde envolve uma ampla variedade de atores sociais, do que somente os profissionais médicos. Além disso, o sistema de saúde deve ser visto ainda como um sistema autopoiético e autorreferente que está estruturalmente acoplado a outros sistemas sociais - sobretudo o direito, na medida em que a Constituição determina que a saúde é um direito de todos os cidadãos, e o sistema político, já que compete ao Estado a obrigação de assegurar o cumprimento desse direito através de políticas públicas.

Vale salientar que não é objetivo deste artigo tecer uma discussão mais aprofundada sobre o sistema de saúde. No entanto, essa definição mais ampla trazida por autores do campo do pensamento sistêmico é fundamental para pensarmos os impactos da pandemia de Covid-19. Certamente, como 
será visto mais à frente, a propagação do Sars-CoV-2 vai muito além da dimensão clínica da doença. A Covid-19 afetou - e tem afetado - a saúde de praticamente todos nós, inclusive daqueles que não foram infectados pelo vírus, mas que acabaram atingidos pelas medidas de distanciamento social; que perderam ou tiveram entes queridos contaminados; ou ainda, que desenvolveram transtornos mentais, como ansiedade, insônia e depressão em razão do pânico relacionado à pandemia.

\section{Elementos conceituais para uma reflexão sociológica da pandemia de Covid-19 à luz da teoria luhmanniana}

A teoria dos sistemas sociais luhmanniana, portanto, observa a sociedade como um gigantesco sistema comunicativo constituído por todas as comunicações possíveis. Esse sistema diferencia-se em incontável número de sistemas e subsistemas sociais, os quais, por sua vez, desempenham tarefas específicas vitais à manutenção e à contínua evolução da sociedade moderna como um todo. Tal diferenciação, entretanto, ocorre - e só ocorre - no âmbito de um contexto de ininterruptas perturbações de um entorno sempre em transformação, nunca estático - Ilya Prigogine (1996) chamou este fenômeno de "sistemas afastados do equilíbrio", considerando o equilíbrio a própria morte de qualquer sistema complexo; considerou também, tal qual Luhmann, que todo o sistema, ao se afastar do equilíbrio, produz ordem (ordem como evolução). Tais sistemas (ou subsistemas) possuem relativa autonomia para lidar/ignorar/rechaçar tais perturbações, como mencionado, reorganizando seus processos internos, mantendo assim um determinado padrão de funcionamento. Sistemas sociais, com efeito, são unidades autoorganizadas (produzem e organizam, elas mesmas, os elementos de que são constituídas) e autorreferentes (procuram sempre manter seu padrão de funcionamento, a partir de um horizonte de expectativas construído com base em uma observação de si e do entorno). Tais características fazem com que os sistemas sociais (eles todos) sejam sistemas relativamente estáveis não em estado de equilíbrio, mas de permanente e relativo estado sutil de 
"equilibração"), os quais conseguem se adaptar às inúmeras perturbações oriundas de seu entorno. ${ }^{8}$ Essa estabilidade, no entanto, deparou-se com uma perturbação de proporções globais e inimagináveis: a propagação da pandemia de Covid-19 e as implicações sistêmicas da imposição de distanciamento social e confinamento, até então inéditos no operar da sociedade contemporânea - pelo menos nos últimos 100 anos.

A disseminação repentina e descontrolada do SARS-CoV-2, considerando-se que se trata de um evento mundial, tem de ser pensada, compreendida e observada à luz da teoria sistêmica luhmanniana, como uma "perturbação" que atinge o funcionamento (a autopoiésis ou autorregulação) de praticamente todos os sistemas sociais, em proporção global. As experiências internacionais com a Covid-19, vivenciadas até então, têm mostrado que o impacto do novo coronavírus afetou, inicialmente, o sistema de saúde. Luhmann (1998), entretanto, em sua teoria sistêmica social, adverte que ao se considerar um sistema específico, os demais sistemas que constituem seu entorno também precisam ser observados.

Para a teoria dos sistemas sociais, como já se discutiu em linhas básicas na primeira seção deste artigo, a sociedade global constitui-se num grande e "único" sistema que abarca todas as comunicações possíveis. Entretanto, esse sistema foi aos poucos se tornando cada vez mais complexo devido à sua diferenciação, ou melhor, à sua "autodiferenciação" funcional. Para Luhmann (1998; 2006), a sociedade contemporânea atingiu um dos mais complexos graus de diferenciação através da especiação de inúmeros subsistemas relativamente autônomos que cumprem funções específicas tanto em nível global, com em nível local.

Para que a compreensão da teoria se torne mais clara, podemos considerar o sistema da ciência, por exemplo, tomando-o como categoria analítica. Esse sistema não existe especificamente neste ou naquele país,

${ }^{8}$ Tomemos como exemplo o sistema econômico mundial. Embora tenha passado por diversas crises, como as duas grandes guerras, a Grande Depressão de 1929 e, mais recentemente, a crise financeira de 2008, o capitalismo sempre conseguiu se reorganizar estruturalmente, adaptando-se à realidade de seu entorno. 
nesta ou naquela região ou localidade (continente, Estado nacional, regiões nacionais, cidades etc.). Ele se constitui num sistema social chamado "sistema de ciência", formado por comunicações que obedecem ao código verdade/não verdade, independentemente da noção de espacialidade ou territorialidade com que usualmente se tem lidado (quase como fronteiras geográficas). Em outros termos, ele é, ao mesmo tempo, um sistema global, regional e local, posto que a ciência se faz presente em toda - ou quase toda - a sociedade mundial, a qual se costuma olhar a partir de suas demarcações territoriais (Luhmann, 1998; 2006). Por certo, o sistema de ciência não existe apenas como categoria analítica; existe, sim, no mundo empírico, mas no sentido aqui explicitado: de forma transnacional e transterritorial e, mesmo assim, como unidade autopoiética, autorreferenciada e que se autodiferencia funcionalmente (especializada, no sentido mais clássico) em subsistemas. A ciência mantém-se como sistema, porque comunicativamente é formada pelo código "verdade/não verdade" - entendo como "verdade" o conhecimento construído dentro dos parâmetros do método científico e como "não verdade" as demais formas de saber, como o senso comum, por exemplo. E mais do que nunca assistimos à evocação desse código no decorrer da pandemia de Covid-19, por exemplo, na constante retórica travada quase que diariamente nos meios de comunicação sobre a verdade/não verdade científica (traduzida em eficácia/não-eficácia) acerca do distanciamento social, do uso de máscaras, da efetividade de determinados tratamentos farmacológicos (como hidroxicloroquina, ivermectina, nitazoxanida), entre outras questões. São exatamente as comunicações - codificadas dessa forma binária - que o sistema da ciência selecionará ou rejeitará, para manter a sua autopoiésis sistêmica.

Imaginemos que toda essa descrição anterior possa ser transposta para o sistema econômico, considerando seus múltiplos subsistemas: o capitalismo, como modo de produção; o mercado financeiro, cujas moedas internacionais adquirem valor sempre relativamente umas às outras; os diferentes setores produtivos (serviço, indústria, agronegócio etc.); consideremos também que o sistema produtivo tem cada vez mais se 
diversificado em inúmeros subsistemas funcionais. A mesma lógica poderia ser transposta, ainda, para os sistemas de ordem política, sejam eles locais, regionais ou internacionais, levando-se em conta, do mesmo modo, suas diversas diferenciações funcionais. Dessa forma, poder-se-ia fazer o mesmo com muitos outros destacados sistemas, como o sistema educacional, o sistema religioso, o sistema jurídico e assim por diante, todos os quais operam, autopoieticamente, a partir de seu código binário específico.

Isso resultaria na percepção inequívoca de que a sociedade, segundo a proposta teórica luhmanniana, apresenta uma codependência evolutiva, conforme menciona o próprio Luhmann (2006). Assim, dependendo do nível de "ruídos" ou "perturbações" comunicativas causadas no entorno sistêmico, surpreendentes reflexos e de diferentes intensidades podem interferir no "sistema global" ou "sistema da sociedade humana", estendendo-se a todas as suas capilaridades subsistêmicas. A infecção pandêmica da Covid-19 causou isso e os reflexos dessa crise terão impacto durante muito tempo sobre os sistemas sociais e a vida de todos nós.

Nessa linha de reflexão teórica, a Figura 1, apresentada a seguir, é justamente um esforço de ilustrar aquilo que se acabou de dizer. Nela, podemos observar a presença de um grande círculo que representa o sistema global da sociedade humana, também podendo ser caracterizado "como sistema-mundo". Esse gigantesco sistema não é formado por pessoas ou coisas, mas somente por todas as comunicações possíveis, as quais, conectadas umas às outras, em rede, formam os sistemas e subsistemas sociais. Esses sistemas, por sua vez, do mesmo modo como os sistemas vivos e de consciência, comportam-se como unidades autônomas, autoorganizadas e autorreferenciadas, que buscam se adaptar, se equilibrar e se autoproteger das mudanças do entorno. Do mesmo modo, a Figura 1 tem o propósito de ilustrar a complexidade, conforme Luhmann (1998), dos diferentes sistemas de comunicação (econômico, jurídico, político, científico etc.). Embora esses sistemas possam parecer operar linearmente e de forma ordenada na dimensão "realística do mundo", eles funcionam, ao mesmo tempo, como entorno uns dos outros, reagindo às perturbações 
do meio, ao mesmo tempo em que as produzem. O operar (individual) de cada um desses sistemas, em específico, e de todos simultaneamente, produz o que Luhmann chama de complexidade máxima. ${ }^{9}$

\section{Figura 1 - Emergência de sistemas e subsistemas de comunicação (diferenciação funcional e coevolução), considerando a totalidade da sociedade global}

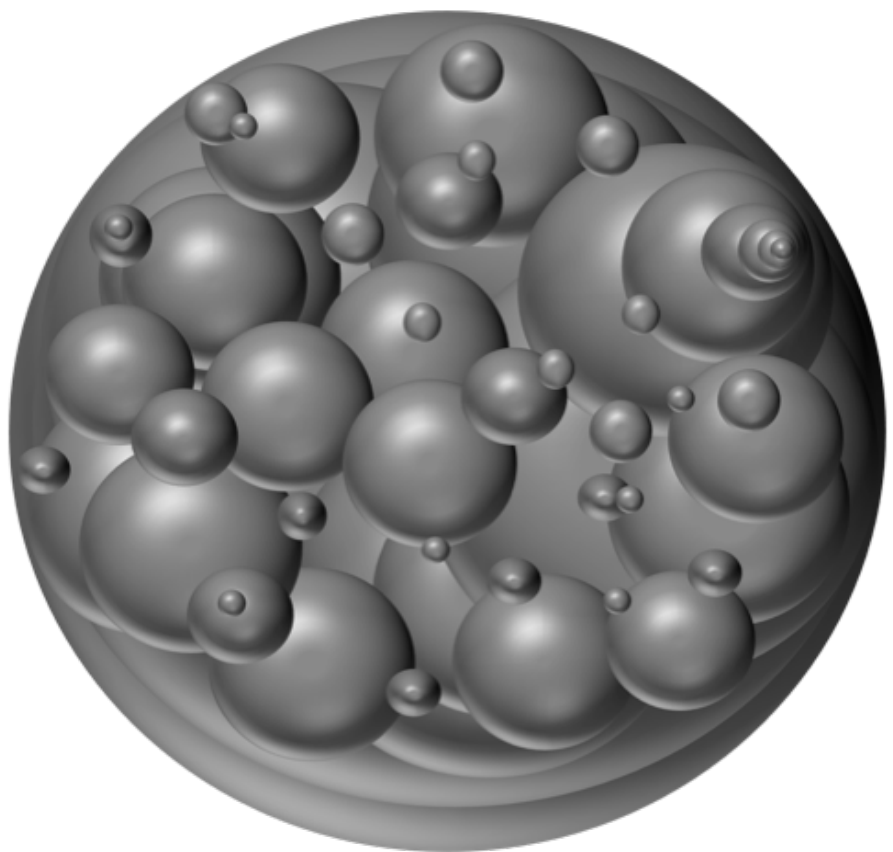

Fonte: elaboração própria. ${ }^{10}$

${ }^{9}$ Certamente, a epistemologia de Roy Bhaskar (2008; 1998), o realismo crítico, ajudaria a melhor compreender a Figura 1. Conforme o autor, a realidade é profunda e (des) horizontalizada - ontologia realista - ao se considerar aquilo que se atualiza e se torna objeto (ato) de conhecimento. O objeto de conhecimento é uma produção social, posto que a totalidade da realidade e do conhecimento da realidade é impossível (objetos intransitivos). ${ }^{10}$ Agradecemos ao Dr. Mahesh Chand, físico indiano e professor convidado do Instituto de Física da Universidade de Brasília (UnB) pelo auxílio na confecção da presente figura, considerando os aspectos conceituais da teoria luhmanniana. 
O esforço - espera-se que bem-sucedido - ao elaborar a Figura 1 foi mais imagético e didático do que propriamente teórico. A teoria luhmanniana, bem como algumas de suas noções centrais, como autorreferência, auto-organização, autoprodução semântica (autopoiésis), acoplamento estrutural, enfim, evocam importantes graus de abstração por si só. Assim, o que a figura pretende é ilustrar uma ideia da complexidade de como os sistemas sociais operam, cada um a partir de sua lógica própria (código binário), no interior de seus próprios, atuando como entorno uns dos outros. Nesse caso, a dificuldade de compreensão reside no fato de que para cada sistema autopoiético (cada esfera emergente da figura), quando observado/selecionado, todos os demais sistemas precisam ser considerados, necessariamente, como entorno. Também é preciso ter em mente que na autopoiésis não há comunicação direta "entre" sistema e entorno, nem entre sistemas "do" entorno. Nesse sentido, todos os sistemas são entorno um do outro, construindo assim uma emaranhada relação (borbulhante, efervescente) de mútuas implicações indiretas, posto que cada sistema mantém a sua circularidade (a sua autonomia e a sua automanutenção como sistema específico de comunicação. ${ }^{11}$ Dito isto, vamos discutir um pouco mais a figura:

a. a esfera maior, isto é a totalidade da figura, é o "sistema global", a sociedade como um todo, no sentido das comunicações que se enlaçam; é a sociedade contemporânea que se diferenciou funcionalmente (porque evoluiu) e se diversificou em diferentes sistemas e subsistemas;

\footnotetext{
${ }^{11} \mathrm{Em}$ um artigo intitulado "Anarquia de base: interação, relação e antiessencialismo na teoria dos sistemas sociais", Neves (no prelo) discute as possibilidades de congruências entre a sociologia relacional e a teoria dos sistemas de Luhmann e, em diálogo com Fuchs (2001), argumenta: "[c]om isso, assinala-se uma imagem da sociedade (...) distante da ordem ou do consenso, sem finalidades acionáveis e sujeita às dinâmicas interacionais que se constituem como formas de vida com capacidade de restabelecer os marcos sobre os quais se constituíram por si mesmas. Nem sistema nem rede, nestes termos, devem ser compreendidos como estruturas rígidas e estáveis (Neves, no prelo, s./p.).
} 
b. ao se olhar para o fundo da figura, é possível reparar que existem esferas (sistemas) que, por sua vez, também se diferenciaram; elas podem ser concebidas como sistemas mais "estáveis", ou mais "antigos", posto que foram os primeiros e os que mais lentamente se desenvolveram, em termos de autopoiésis, ao longo do processo civilizatório (religião, política, direito, economia, ciência, educação etc.);

c. muitos desses sistemas passaram (e continuam) a se diferenciar funcionalmente em diversos outros sistemas parciais, sobretudo a partir da modernidade, fazendo com que a sociedade se tornasse cada vez mais complexa, neste caso, relacional, codependente, coemergente e coevolutiva;

d. o que a figura denota - em conformidade com a teoria luhmanniana, exposta nas secções anteriores - é que sistemas e subsistemas não são constituídos por pessoas, mas por comunicações, as quais são integradas ou rechaçadas de acordo com o código binário específico de cada sistema; a ciência, por exemplo, tende a rechaçar comunicações tidas como "não verdadeiras", quer dizer, não científicas. Esse processo fará com que cada sistema continue se diferenciando, sempre a partir "de dentro", auto-organizando-se indefinidamente enquanto existir - para Luhmann, isso caracteriza o atual nível de complexidade social;

e. se focarmos (selecionarmos) um determinado sistema para conhecer o seu comportamento autopoiético, todos os demais sistemas deverão ser vistos como entorno do sistema selecionado; e mais, esses sistemas, considerando seus processos evolutivos individuais, afetarão, de algum modo, o sistema focado, "irritando-o" a produzir mais e mais autoorganização e processos de diferenciação funcionais - ou simplesmente a lutarem para se manter como tais: "vivos" do ponto de vista de suas "poieses";

f. com esta simultaneidade coevolutiva entre sistema e entorno, Luhmann pretende demonstrar o crescente aumento de complexidade, a partir de uma "inflação" - posto que os sistemas constroem ordem (negentropia) 
a partir da ordem pré-existente (emergência) - interna do sistema global; e

g. assim, a "realidade" do fenômeno social descrito pela teoria autopoiética dos sistemas é concebida como um emaranhado transterritorial de sistemas comunicacionais, que se mantêm operando recursivamente, uma vez que só são sensíveis às comunicações que têm implicações com os seus códigos binários, mas que também não os destruam.

Com base nesses elementos teóricos, buscaremos a seguir construir um olhar empírico acerca do impacto sistêmico (perturbação) causado pela pandemia de Covid-19 no funcionamento dos sistemas e subsistemas sociais.

\section{O impacto da pandemia de Covid-19 sobre os sistemas e subsistemas sociais: caminhos para uma análise empírica}

O arcabouço conceitual do modelo luhmanniano - como buscaram sustentar as reflexões teóricas desenvolvidas neste artigo - pode embasar importantes pesquisas futuras dedicadas à investigação dos impactos causados pela pandemia do coronavírus ao funcionamento dos sistemas da sociedade.

Como já mencionado, a Covid-19 foi apresentada ao mundo em 31 de dezembro de 2019, data em que médicos chineses alertaram a OMS sobre a descoberta de um grupo de pacientes que apresentava sintomas de pneumonia associados a uma doença até então desconhecida, supostamente vinculada a um mercado de frutos do mar em Wuhan, cidade chinesa com 11 milhões de habitantes (Zhu et al., 2020). Através de sequenciamento e isolamento laboratorial, pesquisadores chineses descobriram que os sintomas se relacionavam a um novo tipo de coronavírus que causa síndromes respiratórias graves em humanos. É importante destacar, nesse interim, que desde a década de 1930 foram descobertos diversos coronavírus que atacam aves domésticas, causando problemas respiratórios, gastrointestinais, neurológicos, dentre outros, a esses animais. Até hoje, são conhecidos apenas sete desses coronavírus capazes de afetar os seres humanos. Quatro deles 
causam sintomas de um resfriado comum; três, no entanto, podem causar infecções respiratórias muito severas, sendo responsáveis por surtos de pneumonia fatal no início do século XXI: o SARS-CoV, identificado em 2002, na China, causador da Síndrome Aguda Respiratória (SARS); o Mers-CoV, descoberto em 2012, na Arábia Saudita, causador da Síndrome Respiratória do Oriente Médio (MERS); e, finalmente, o SARS-CoV-2, descoberto na China, no final de 2019, causador da Covid-19 (Tesini, 2020).

A velocidade de alastramento da Covid-19 - muito mais rápida do que a da SARS, doença que matou aproximadamente 800 pessoas, em 2002, e que a MERS, a qual levou a óbito mais de 900 pacientes, em 2012 - atraiu a atenção das autoridades de saúde de todo o planeta. A primeira morte em decorrência da Covid-19 ocorreu pouco tempo após a descoberta do novo coronavírus, em 11 de janeiro de 2020. Dois dias depois, foi identificado, na Tailândia, o primeiro caso da doença fora da China, em um indivíduo que recentemente havia viajado para Wuhan. No dia 23 do mesmo mês, o governo chinês isolou Wuhan e determinou o fechamento obrigatório de aeroportos, estações ferroviárias e estradas, no intuito de conter a propagação do SARS-CoV-2. Ainda em janeiro, foram identificados os primeiros casos de contaminação em países como Japão, Coreia do Sul, Taiwan, Austrália, França, Alemanha e Estados Unidos. Em 26 de fevereiro, foi identificado o primeiro caso de infecção de Covid-19 no Brasil. Em março, o mundo assistiu atônito à escalada no número de casos e de óbitos, e ao colapso dos sistemas de saúde de algumas das principais nações.

O principal desafio no combate à Covid-19 é o fato de se tratar de uma doença ainda nova, altamente contagiosa ${ }^{12}$ e extremamente letal em indivíduos idosos e/ou com comorbidades, tais como diabetes e cardiopatias. Até o momento da redação deste artigo (março de 2021), o SARS-CoV 2

12 As informações preliminares apontam que o novo coronavírus sobrevive várias horas ou até mesmo dias em superfícies como plástico, tecido ou metal, inclusive nas roupas e no dinheiro. Além disso, as gotículas de saliva geradas por tosse (um dos principais sintomas da doença) ou espirro fazem também com o que vírus permaneça no ar por vários minutos. 
já contaminou mais de 117,3 milhões de pessoas, levando 2,6 milhões a óbito. ${ }^{13}$ É importante frisar, nesse contexto, que ao contrário da gripe espanhola, cuja propagação foi impulsionada pela Primeira Guerra Mundial, a Covid-19 espalhou-se pelo planeta rapidamente em virtude da existência de um sistema global de transporte (vindo pouco tempo depois a reduzilo ao mínimo ou inviabilizá-lo temporariamente). O fluxo constante de voos internacionais fez com que em menos de um mês o coronavírus se alastrasse de uma província chinesa para diversos países, muito antes de as autoridades de saúde terem percebido a real gravidade da doença - vale reiterar que a OMS elevou a contaminação de SARS-CoV-2 ao status de pandemia apenas em 11 de março de 2020, momento em que um grande número de países já havia registrado centenas de casos de contaminação.

Como vimos, ao chegar em uma nova região, a Covid-19 inicialmente impacta (perturba, em termos sistêmicos) o sistema de saúde, que logo entra em colapso. É preciso destacar, dessa forma, que, embora a imensa maioria dos indivíduos infectados pelo SARS-CoV-2 apresente sintomas leves ou moderados, ou então não apresente sinal algum de infecção pela doença (as chamadas pessoas assintomáticas), estima-se que aproximadamente 10 a 15\% dos pacientes diagnosticados desenvolverão sintomas graves ou críticos, necessitando de internação hospitalar. Desse total, boa parte exigirá internação em Unidades de Terapia Intensiva (UTIs), com uso de ventilação mecânica. Além disso, os pacientes que precisam de terapia intensiva permanecem internados, em média, por mais de 14 dias. Por esse motivo, justamente, é que a Covid-19 acentua bruscamente a curva epidemiológica - número de novos casos de infecção que demandam internação $(\mathrm{x})$ versus o tempo que o sistema de saúde necessita para tratar os pacientes já internados e liberar leitos (y).

\footnotetext{
13 É preciso destacar, no entanto, que esses são apenas os dados oficiais notificados pelas autoridades governamentais. Em muitos países, como o próprio Brasil, há uma grande subnotificação de registros de infecção, bem como no número de mortes. Com efeito, o número real de pessoas infectadas e mortas pelo vírus tende a ser muito maior do que as estatísticas oficiais.
} 
Consequentemente, em questão de poucos dias, a pandemia de Covid-19 pode facilmente sobrecarregar o sistema de saúde, levando ao seu total esgotamento, principalmente nas regiões com grande contingente de pessoas que fazem parte dos grupos de risco. No Brasil, como dito, o primeiro caso de infecção foi diagnosticado no final de fevereiro de 2020. Em junho do mesmo ano, já eram contabilizados mais de 1 milhão de casos em todo o país e um total de 48 mil mortes oficiais por Covid-19. No instante em que esse artigo é finalizado (março de 2021), isto é, um ano após o início da pandemia no território brasileiro, o número de infecções já passa de 11 milhões e o de óbitos de 270 mil. Infelizmente, é bastante provável que estes números ainda aumentarão consideravelmente. Dados da Fiocruz ${ }^{14}$ apontam que neste exato momento a ocupação de leitos de UTI passa de 90\% em 15 capitais e 13 estados. Capitais como Porto Alegre, Porto Velho e Campo Grande, inclusive, já ultrapassaram os 100\% de ocupação, com pacientes na fila aguardando um leito para tratamento intensivo. E não obstante os esforços sobretudo dos governos municipais e estaduais em criar novos leitos de UTI, a propagação do vírus se dá em velocidade muito maior, principalmente com o surgimento de novas cepas do Sars-CoV-2, que aumentam a carga viral dos indivíduos contaminados e, consequentemente, aceleram o ritmo de propagação do vírus, sobrecarregando ainda mais o sistema de saúde.

Desse modo, se considerarmos, a partir da ótica sistêmica, que tanto o agir como o não agir são comunicações possíveis de seleção e se constituem em entorno específico de determinados sistemas, assistimos, assim, desde o início da pandemia, a determinados sistemas de saúde colapsarem, justamente por não estarem preparados para a violenta irritação/perturbação sofrida, gerada pela necessidade de tratamento intensivo de um enorme contingente de sistemas orgânicos e psíquicos - os seres humanos - atingidos pelo coronavírus. Precisamos ter em mente, também, o fato de que como o sistema de saúde mantém codependência com subsistemas econômicos

${ }^{14}$ Informação disponível em: https://agenciabrasil.ebc.com.br/saude/noticia/2021-03/fiocruzocupacao-de-utis-passa-de-90-em-15-capitais-e-13-estados. Acesso em: 10 mar. 2021. 
- sobretudo aqueles voltados à produção de EPIs, testes virais e tecnologias para leitos de terapia intensiva, entre outros -, estes subsistemas também acabaram sobrecarregados pela violenta irritação/perturbação causada pela propagação do coronavírus. O resultado da falta desses materiais, por sua vez, foi também uma irritação sistêmica sobre o sistema de saúde, que, frente ao alto número pacientes infectados pelo vírus e à falta de recursos não só materiais, mas também humanos, não conseguiu operar adequadamente, chegando ao colapso - o que também gerou inúmeras perturbações sobre o funcionamento dos demais sistemas sociais.

A elevação imediata do número de óbitos, por exemplo, - em termos luhmannianos, a aniquilação de sistemas orgânicos e sistemas psíquicos neles acoplados - causados pelo novo coronavírus perturbou drasticamente o subsistema funerário, bem como o sistema religioso, considerando as diferentes religiões e as crenças comunicativas que o sustentam. Na Itália e em Nova lorque, e posteriormente no próprio Brasil, assistimos a centenas de corpos sendo transportados e armazenados em caminhões frigoríficos. No Brasil, cidades como Manaus e São Paulo foram as primeiras onde os corpos das vítimas tiveram de ser enterrados em valas comuns em cerimônias coletivas que duravam em torno de 10 a 15 minutos. Já no Equador, a propagação da Covid-19 levou à falta de caixões e ao colapso dos cemitérios e estabelecimentos funerários, o que levou muitas famílias a abandonarem os corpos de seus entes mortos pelas ruas de Guayaquil, até que fossem recolhidos pelas autoridades sanitárias.

A pandemia de Covid-19, do mesmo modo, causou uma profunda irritação ao sistema de ciência, no sentido de que este desse uma resposta sobre como neutralizar o entorno nocivo (o coronavírus) inóspito ao acoplamento estrutural de diversos sistemas e subsistemas da sociedade. Tal perturbação se deu no sentido da pressão para a produção de uma vacina ou de fármacos realmente eficazes, posto que dada a velocidade de disseminação da Covid-19, o que os governos nacionais dispuseram no decorrer de 2020 como "resposta" eficaz para conter o avanço do vírus foi unicamente o distanciamento social. Por isso que, em março de 
2020, o diretor da OMS, Tedros Adhanom Ghebreyesus, afirmava que o distanciamento é a "melhor e única maneira de proteger a vida, os meios de subsistência e as economias [...]. Sem desculpas, sem arrependimentos". ${ }^{15}$

O distanciamento social, entretanto, ao se considerar os principais elementos da teoria sistêmica luhmanniana, traz inúmeras consequências, isto é, perturbações comunicativas que afetam diretamente o funcionamento dos diversos sistemas sociais, dadas as relações de acoplamento estrutural existentes entre eles, já destacadas anteriormente. A depender do regime político de cada região, considerando que os sistemas políticos estão organizados em subsistemas com regimes políticos distintos mais ou menos democráticos (mesmo ao se considerar as diferentes democracias liberais), mais ou menos autoritários (mesmo ao se considerar os regimes socialistas, ditatoriais e aqueles híbridos, com economia de mercado muito forte, mas com escassas liberdades individuais), as experiências de distanciamento social ocorreram de forma distinta com relação à sua eficiência. Na China, por exemplo, se os dados oficiais divulgados pelo governo chinês são verdadeiros, o isolamento completo da região de Wuhan durante mais de dois meses conseguiu controlar o avanço da pandemia. No Brasil, no entanto, onde as medidas de isolamento foram adotadas quase como "conta gotas" por estados e municípios, sem um planejamento em nível nacional, gerando um efeito sanfona de abre/fecha as atividades econômicas, a pandemia fugiu ao controle. ${ }^{16}$

Nesse sentido, quando observamos as medidas de distanciamento social, não podemos perder de vista que algumas culturas, como a brasileira

\footnotetext{
15 Informação disponível em: https://www.terra.com.br/vida-e-estilo/saude/oms-reforca-propostade-isolamento-social-contra-coronavirus,2dbee08f5954bcd3134bc462a2ff5424en3nzx2y.html. Acesso em: 30 mar. 2020.

16 Ainda no que diz respeito às medidas de distanciamento social adotadas ao redor do mundo para tentar controlar o avanço da pandemia, vale lembrar aqui o caso emblemático das Filipinas, país onde o presidente Rodrigo Duterte autorizou as forças policiais a atirarem contra os cidadãos que desrespeitassem as determinações adotadas pelo governo nacional para tentar impedir o avanço descontrolado do coronavírus. Lembremos também o caso da Índia e da Venezuela, cujos vídeos que circularam pela internet mostravam os cidadãos que saíram às ruas apanhando dos policiais (com varas ou relhos), sendo obrigados a voltar para casa.
} 
e mesmo as latino-americanas, por exemplo, apresentam maior proximidade entres as pessoas (sistemas orgânicos) de forma absolutamente involuntária. Como se sabe, cultura é uma dimensão profundamente introjetada, e quando exteriorizada, se faz de forma automática, não refletida, conforme nos mostra o próprio conceito de habitus de Pierre Bourdieu (1989), e muitos dos estudos culturais. Portanto, o sistema cultural é uma dimensão importante a ser considerada na eficácia do distanciamento social em determinadas regiões, isto é, na adesão ou não por parte da população. ${ }^{17}$

Nessa esteira da reflexão sobre os impactos da pandemia sobre os sistemas sociais, não podemos esquecer ainda aquele causado pela crise sanitária do coronavírus sobre o sistema de educação, o qual foi duramente perturbado com a suspensão das aulas presenciais. Segundo o monitoramento da Unesco (2020), a pandemia de Covid-19 levou mais de 150 países a implementarem o fechamento de escolas e universidades, o que afetou mais de $91 \%$ da população estudantil do planeta. Muitas instituições de ensino procuraram manter suas atividades acadêmicas através do ensino remoto emergencial. Todavia, os estudantes mais pobres acabam sendo afetados, sobretudo, porque não há como esperar que alunos oriundos de famílias de baixa renda - as quais, muitas vezes, sequer têm comida para pôr sobre a mesa diariamente - tenham acesso a tecnologias e internet de qualidade para que possam estudar a distância.

Outro sistema social que foi igualmente perturbado pela Covid-19 foi o sistema esportivo. O distanciamento social em decorrência do coronavírus levou à suspensão ou ao cancelamento de incontáveis eventos e competições esportivos pelo mundo. O maior exemplo desse impacto sistêmico no sistema de esporte foi o adiamento das Olímpiadas, as quais seriam realizadas no Japão, em junho 2020, mas acabaram transferidas para junho de 2021,

\footnotetext{
17 Sobre a eficácia e a adesão da população ao distanciamento social, também não podemos desconsiderar a situação de pobreza vivenciada por milhões de brasileiros, para os quais ficar em casa isolados durante dias ou até mesmo semanas é um luxo o qual não podem se dar. Como esperar que trabalhadores informais, como motoristas de aplicativo, cabeleireiras, vendedores ambulantes, enfim, pessoas que muitas vezes trabalham durante o dia para comer à noite, adiram de bom grado ao imperativo "fique em casa"?
} 
sendo que no momento restam ainda incertezas sobre sua realização. Além disso, mesmo clubes de futebol bilionários, como o Barcelona e Real Madri, tiveram de reduzir temporariamente o salário de seus jogadores em até 70\% para conseguir enfrentar os prejuízos financeiros causados pela paralização de campeonatos em virtude da pandemia. Mas a situação é ainda muito mais grave para os atletas que sobrevivem com os escassos patrocínios que recebem, sobretudo porque, no contexto da crise econômica global desencadeada pela Covid-19, muitas empresas estão sendo obrigadas a cortar gastos, dentre eles, o investimento em patrocínios esportivos.

No que refere ao já referido sistema religioso, este foi perturbado, sistemicamente, sobretudo, com as medidas que proíbem a realização de missas e cultos, no intuito de evitar a aglomeração de pessoas. A comunidade católica mundial, por exemplo, assistiu ao Papa Francisco realizar a famosa missa pascal em uma Basílica de São Pedro vazia, em meio à pandemia de coronavírus. É preciso destacar, nesse sentido, que o fechamento de igrejas e templos e a suspensão de reuniões é um assunto que divide as opiniões dos líderes religiosos. Alguns deles defendem que a suspensão temporária das missas e cultos presenciais é uma forma de proteger os fiéis e de evitar a propagação do novo vírus que se alastra pelo mundo. Outros, por sua vez, sustentam que é fundamental manter as igrejas abertas neste momento para dar esperança e suporte espiritual à população.

Não obstante o impacto causado pela pandemia de Covid-19 sobre esses sistemas e subsistemas sociais, um deles merece aqui atenção especial: o sistema econômico. O distanciamento social - único remédio de que que os governos nacionais tiveram à sua disposição no decorrer de 2020 para conter o avanço do vírus -, numa sociedade sistêmica, interativa, cujos processos de codependência tornaram-se profundamente dinâmicos e acelerados, tem catastróficos efeitos colaterais sobre a economia, a médio e longo prazo, sem falar no seu impacto imediato. Em uma sociedade global, com aproximadamente 7,6 bilhões de indivíduos, sem dúvida, o sistema econômico e seus subsistemas (como o modo de produção, a circulação planetária de mercadorias, o mercado de câmbio, o sistema de emprego 
etc.) são duramente impactados, sobretudo porque, confinadas ou não, as pessoas precisam continuar se alimentando. Justamente por esse motivo é que muitos governos resistiram (e ainda resistem) em adotar medidas de distanciamento social que envolvem o fechamento das atividades econômicas presenciais. As perturbações sistêmicas que essas medidas geram - considerando o sistema econômico internacional e seus diversos subsistemas regionais/locais - são avassaladoras, como veremos mais adiante.

Entretanto, a não aplicação do distanciamento social, de forma rígida, pode igualmente ter efeitos tão ou até mais devastadores sobre a economia, do que sua não aplicação. Podemos tomar a Itália como exemplo. Em 28 de fevereiro de 2020, quando menos de 20 mortes haviam sido oficializadas naquele país e quando muitas cidades sequer haviam registrado casos de Covid-19, prefeitos e governadores começaram a adotar as primeiras medidas de distanciamento social, como suspensão das aulas presenciais e a proibição de aglomerações em locais públicos, para tentar conter o avanço do novo coronavírus. Todavia, prevendo o impacto que essas decisões teriam sobre a economia italiana e sobre o sistema econômico global (não podemos esquecer, por exemplo, que a Itália faz parte da União Europeia), o primeiro-ministro italiano, Giuseppe Conte, criticou duramente as medidas, conseguindo inclusive derrubar algumas delas judicialmente. A não adoção do único remédio então conhecido, o distanciamento social, refletiu imediatamente no aumento exponencial do número de mortes a cada dia. Menos de duas semanas depois, no dia 9 de março, quando o número de óbitos na Itália chegava a quase 500, Conte determinou o fechamento de todas as atividades não essenciais em todo o país. ${ }^{18}$ Mas a decisão foi tomada tarde demais: dez dias depois, o país contabilizava 3.405 mortes por Covid-19.

Assim como o primeiro-ministro italiano, o ex-presidente dos Estados Unidos, Donald Trump, também relutou em adotar as medidas de distanciamento social orientadas pela OMS para conter o avanço do

18 Informações disponíveis em: https://brasil.elpais.com/internacional/2020-03-25/italia-pagoupreco-alto-ao-resistir-a-medidas-de-isolamento-social-para-conter-coronavirus.html. 
coronavírus. Em janeiro, quando foi oficializado o primeiro caso de Covid-19 no país, Trump afirmou que tudo estava sob controle e ficaria bem, já que se tratava de uma única pessoa infectada que havia chegado da China. Em 9 de março, quando os casos confirmados eram 546 e óbitos 22, Trump voltou a atacar as medidas de distanciamento, ao publicar em sua conta oficial no Twitter que a gripe comum mata milhares de americanos por ano e "a vida e a economia seguem". Contudo, no dia 25 de março, momento em que o número de infecções já passava dos 65 mil e o de mortes mais de 700, após ser aconselhado por especialistas em saúde, Trump mudou o tom ao afirmar que não poria fim às medidas de distanciamento no país de forma precipitada, e que estava preparado para fazer o que fosse preciso para salvar vidas. Assim como na Itália, as medidas de distanciamento nos Estados Unidos foram adotadas tarde demais: até agora (março de 2021), é o país com maior número de casos (29 milhões) e de óbitos (527 mil) oficializados.

A aplicação do remédio - o distanciamento social - e a sua não aplicação tornaram-se um dos maiores dilemas internacionais. Um relatório publicado pelo Fundo Monetário Internacional (FMI) em abril de 2020 projetou que nesse ano o PIB global poderia ter uma redução de 3\%, pior desempenho desde a crise de 1929. ${ }^{19}$ Até o pujante sistema econômico norte-americano apresentou números catastróficos durante a pandemia, nunca antes vistos, mesmos nas piores crises vivenciadas pelo país ao longo de sua história. As estimativas do FMI apontam que a economia dos Estados Unidos teve um encolhimento de quase 6\% em 2020. Até o momento, mais de 45 milhões de norte-americanos já solicitaram ao governo o recebimento do seguro-desemprego. No segundo trimestre de 2020, a economia norte-americana registrou uma queda histórica de quase 33\%.

Se até mesmo a forte economia estadunidense apresentou números calamitosos diante dos efeitos da pandemia de coronavírus, o cenário para os

19 Informações disponíveis em: https://www.ipea.gov.br/cartadeconjuntura/index.php/category/ economia-mundial/\#: : :text=As\%20proje\%C3\%A7\%C3\%B5es\%20do\%20Fundo\%20 Monet\%C3\%A1rio,5\%2C8\%25\%20em\%202021. Acesso em: 10 mar. 2021. 
países mais pobres e emergentes é ainda mais avassalador. No Brasil, a taxa de desemprego bateu recorde fechando em 13,5\%, o que representa mais de 13 milhões de desempregados. O PIB nacional, por sua vez, registrou uma queda recorde de 4,1\% - a maior desde 1996.

A perturbação que a pandemia de Covid-19 causa sobre o sistema de emprego tende a ser pior em países mais pobres, nos quais há um grande contingente de trabalhadores informais. No Brasil, cerca de 41,1\% da população ocupada (38,8 milhões de pessoas) vive na informalidade. $\mathrm{O}$ relatório "Women and men in the informal economy", publicado em 2018 pela Organização Internacional do Trabalho (OIT) aponta que mais de 61\% da população ocupada no mundo (cerca de dois bilhões de trabalhadores) vivem na economia informal. A imensa maioria encontra-se nas regiões mais pobres, como a África, onde mais de 85\% dos trabalhadores vivem na informalidade (ILO, 2018). Certamente, a maior parcela desses indivíduos não tem condições financeiras para interromper suas atividades laborais e permanecer em confinamento domiciliar por mais do que alguns poucos dias. Logo, para permanecer em confinamento, essas pessoas necessitarão de auxílio por parte do Estado - o que representa um enorme desafio aos governos nacionais, muitos dos quais já se encontram historicamente abarrotados em dívidas e problemas econômicos e sociais crônicos.

A pandemia de Covid-19, com efeito, conseguiu perturbar, profunda e simultaneamente, o funcionamento de praticamente todos os sistemas sociais, alastrando-se pela sociedade, da mesma forma como um vírus se alastra pelo organismo. Há estudos que apontam que o confinamento domiciliar gerado em virtude do novo coronavírus está relacionado, por exemplo, ao aumento de casos de violência doméstica contra a mulher. Dados do Ministério Público de São Paulo revelam que, em menos de um mês de distanciamento, houve um aumento de 30\% no número de medidas protetivas de caráter de urgência, as quais passaram de 1.934 em fevereiro, para 2.500 em março de $2020 .^{20}$ Por sua vez, um levantamento

${ }^{20}$ Informação disponível em: https://g1.globo.com/sp/sao-paulo/noticia/2020/04/13/casos-deviolencia-contra-mulher-aumentam-30 percent-durante-a-quarentena-em-sp-diz-mp.ghtml. 
realizado pelo Fórum Brasileiro de Segurança Pública mostra que quatro estados da federação - São Paulo, Rio Grande do Norte, Mato Grosso e Acre - registraram um aumento no número de feminicídios cometidos dentro do lar em março de 2020, em comparação com o mesmo mês no ano anterior. ${ }^{21}$ É importante frisar que a violência contra a mulher é um problema crônico na história do Brasil. No entanto, com as medidas de distanciamento social, muitas mulheres acabam ficando mais tempo dentro de casa em companhia de seus agressores, o que aumenta o risco de sofrerem algum tipo de violência. Além disso, justamente por terem de ficar em confinamento domiciliar, muitas delas acabam por não ir até uma delegacia para fazer a denúncia - situação esta que constitui um obstáculo a mais às autoridades do sistema de segurança pública que lutam para combater esse grave problema social.

Além de gerar perturbações sobre os sistemas sociais, a pandemia de Covid-19 também causou profundas perturbações sobre os sistemas psíquicos. Ficar em confinamento domiciliar durante vários meses, sem poder realizar atividades simples do dia a dia, como trabalhar, ir à escola ou à universidade, reunir-se com amigos e familiares, ir ao cinema, à igreja, sair para almoçar ou jantar fora, ir à academia, enfim, nos causou inúmeras irritações e estresses mentais. Além disso, assistir diariamente às informações veiculadas nos meios de comunicação acerca do alastramento da Covid-19, do aumento do número de óbitos, da falta de um tratamento eficaz contra o vírus, do colapso dos hospitais, do surgimento de novas cepas virais que podem colocar em risco a eficácia das vacinas, enfim, pode ser o gatilho para sentimentos como ansiedade, medo e pânico. Soma-se a isso o receio de perder o emprego, para aqueles que ainda o têm, ou o completo desespero daqueles que já o perderam.

As cenas marcantes de dezenas de caixões amontoados em depósitos na Itália; de corpos de vítimas de Covid-19 empilhados em caminhões frigoríficos em Nova York; de corpos abandonados pelas ruas de Guayaquil,

${ }^{21}$ Informação disponível em: https://g1.globo.com/jornal-nacional/noticia/2020/04/16/violenciacontra-a-mulher-aumentou-em-marco-em-quatro-estados-diz-levantamento.ghtml. 
rodeados por urubus, ou então queimados em cemitérios locais; ou ainda, as cenas de pacientes agonizando e morrendo por falta de oxigênio em Manaus são de um verdadeiro filme apocalíptico de terror, nunca antes visto pelas gerações atuais. Tais cenas narradas nos noticiários, normalmente, vêm acompanhadas de previsões catastróficas para a economia, as quais apontam recordes de desemprego em massa, em um cenário pós-pandemia marcado por uma recessão histórica. Assistimos a esse quadro caótico enquanto estamos confinados em nossos lares, tentando proteger a nós e a nossos familiares de um inimigo invisível. O resultado disso é um profundo estresse psicológico que atinge principalmente aqueles indivíduos que já sofrem com algum tipo de transtorno mental, como ansiedade, depressão, insônia, síndrome do pânico, distúrbios alimentares, dentre outros. A empresa de assistência médica americana Express Scripts, que presta serviços a mais de trinta milhões de clientes, aponta que o consumo de medicamentos para transtorno psicológico nos Estados Unidos aumentou consideravelmente durante a quarentena. Segundo a empresa, o maior aumento ocorreu na prescrição de medicamentos para o tratamento de ansiedade, os quais tiveram um aumento de $34,1 \%$ entre meados de fevereiro a meados de março. Por sua vez, as prescrições para antidepressivos e distúrbios do sono apresentaram um aumento $18,6 \%$ e $14,8 \%$, respectivamente, no mesmo período (Luddy, 2020).

Os efeitos do novo coronavírus, como percebemos, perturbam o funcionamento não apenas dos sistemas e subsistemas sociais (como o sistema de saúde, o sistema funerário, o sistema de deslocamento de mercadorias, o sistema laboral, o sistema político, o sistema educacional, o sistema econômico), mas também os sistemas psíquicos. Em outros termos, a pandemia trata-se de uma ameaça à sociedade humana como um todo. $\mathrm{Na}$ verdade, os ruídos, mais que isto, os desequilíbrios gerados por essa pandemia - que opera como entorno nocivo ao acoplamento estrutural dos diversos sistemas sociais de comunicação - alastram-se, circundando as mais diversas esferas comunicativas dos diferentes sistemas que compõem a sociedade. Mais grave ainda é que a pandemia afeta cada indivíduo, em 
particular, considerado pela teoria dos sistemas como sistema orgânico e que serve de acoplamento do sistema psíquico, fonte de todas as comunicações possíveis que constituem os mais diversos sistemas da sociedade e o sistema social como um todo.

A Covid-19, portanto, é uma doença que vai muito além da dimensão clínica. Acima de tudo, trata-se de uma enfermidade que atinge todo o funcionamento da sociedade, tanto no nível local, quanto numa dimensão global. Não queremos dizer, com isto, que a pandemia coloca em xeque o funcionamento dos sistemas sociais. Longe disso: justamente por sua capacidade autopoiética, os sistemas da sociedade conseguem se adaptar às mais diversas crises - o sistema econômico é um grande exemplo. No entanto, o que é inegável - e este artigo procurou demonstrar - é que a propagação da Covid-19 traz um conjunto de perturbações que atinge, simultaneamente, os diferentes sistemas e subsistemas sociais. O pensamento sistêmico luhmanniano, por sua vez, consegue mobilizar importantes ferramentas conceituais que possibilitam a compreensão sociológica dos impactos sociais dessa pandemia.

No cenário pós-pandêmico, caberá aos cientistas sociais mobilizar ferramentas teórico-metodológicas para avaliar até que ponto a pandemia levou a um reordenamento dos sistemas sociais. Que mudanças de fato ocorreram no seu funcionamento? Que dinâmicas sociais surgiram ao longo da pandemia e permaneceram ao seu término (como o home office, por exemplo)? Como a pandemia alterou a vida social ao redor do globo? Enfim, essas e outras questões precisarão ser respondidas. A teoria dos sistemas sociais, a nosso ver, constitui um rico modelo teórico, cujo arcabouço conceitual poderá auxiliar no desenvolvimento de pesquisas futuras relacionadas aos reflexos da pandemia. Principalmente, quando consideramos que a Covid-19 não apenas afeta a sociedade como um todo, mas também gera uma rede sistêmica de mútuas perturbações entre os sistemas sociais. A teoria luhmanniana, com efeito, apresenta vantagens investigativas enquanto referencial teórico, na medida em que possibilita um olhar sistêmico (uma observação, diria Luhmann) amplo sobre como 
cada sistema foi individualmente impactado pela pandemia, e também sobre como esse impacto gerou perturbações sobre os demais sistemas do entorno.

Léo Peixoto Rodrigues é Doutor em Sociologia pela Universidade Federal do Rio Grande do Sul, professor dos Programas de Pós-Graduação em Sociologia e em Ciência Política da Universidade Federal de Pelotas.

$\triangle$ leo.peixotto@gmail.com

Éverton Garcia da Costa é Doutor em Sociologia pela Universidade Federal do Rio Grande do Sul e professor no Instituto Federal de Educação, Ciência e Tecnologia Sul-Riograndense (IFSul).

$\bowtie$ eve.garcia.costa@gmail.com

\section{Referências}

1. COSTA, Everton G. A avalanche chegou? Um estudo sobre o crescimento da educação superior a distância. 2018. Tese (Doutorado em Sociologia, Programa de Pós-Graduação em Sociologia - Universidade Federal do Rio Grande do Sul, Porto Alegre, 2018.

2. BHASKAR, Roy. A realist theory of science. Londres e Nova York: Routledge, 2008.

3. BHASKAR, Roy. Philosophy and scientific realism. In: ARCHE, Margaret; BHASKAR, Roy; COLLIE Andrew et al. Critical realism: essential readings. Londres e Nova York: Routledge, 1998. p. 16-46.

4. BOURDIEU, Pierre. O poder simbólico. Lisboa: Difel, 1989.

5. CORSI, Giancarlo; ESPOSITO, Elena; BARALDI, Claudio. Glosario sobre la teoria social de Niklas Lukann. México: Anthropos, Universidad Iberoamericana, Iteso, 1996.

6. FUCHS, Stephan. Against essentialism: a theory of culture and society. Cambridge, MA: Harvard University Press, 2001.

7. ILO. Women and men in the informal economy: a statistical picture. 3. ed. 2018. Geneva: International Labour Office, 2018. Disponível em: https://www. ilo.org/wcmsp5/groups/public/---dgreports/---dcomm/documents/publication/ wCms_626831.pdf

8. LUDDY, Jennifer. America's state of mind: use of mental health medications increasing with spread of coronavirus. Express Scripts. News, 16 abr. 2020. 
Disponível em: https://www.express-scripts.com/corporate/articles/americasstate-mind-use-mental-health-medications-increasing-spread-coronavirus

9. LUHMANN, Niklas. Sistemas sociais: esboço de uma teoria geral. Petrópolis: Vozes, 2016.

10. LUHMANN, Niklas. La sociedad de la sociedad. México: Iberoamericana/ Herder, 2006.

11. LUHMANN, Niklas. Introdução à teoria dos sistemas. Petrópolis: Vozes, 2009.

12. LUHMANN; Niklas. A improbabilidade da comunicação. Lisboa: Veja, 2001.

13. LUHMANN, Niklas. Sistemas sociales: lineamentos para una teoría general. Rudí (Barcelona): Anthropos, 1998.

14. LUHMANN; Niklas. O conceito de sociedade. In: NEVES, Clarissa E. B.; SAMIOS, Eva M. B. Niklas Luhmann: a nova teoria dos sistemas. Porto Alegre: Editora da UFRGS, 1997.

15. LUHMANN, Niklas. Organizaçción y decisión. Autopoiésis, accion y entendimiento comunicativo. Barcelona: Anthropos, 1997a.

16. MARTINI, Sandra Regina. Construção do sistema social da saúde a partir da teoria sistêmica de Niklas Luhmann. Revista de Direito Sanitário, São Paulo, v. 16 , n. 1, p. 112-127, 2015.

17. MATURANA, Humberto. O que é ver? In: MAGRO, Cristina; GRACIANO, Miriam; VAZ, Nelson. A ontologia da realidade. Belo Horizonte: Ed. UFMG, 1997.

18. MATURANA, Humberto; VARELA, Francisco. De máquinas e seres vivos. Autopoiese: a organização do vivo. Porto Alegre: Artes Médicas, 1998.

19. MATURANA, Humberto; VARELA, Francisco. Autopoiesis and cognition: the realization of the living. Londres: D. Reidel Publishing Company, 1980.

20. NEVES, Fabrício M. Anarquia de base. Interação, relação e antiessencialismo na teoria dos sistemas sociais. (No prelo).

21. PRIGOGINE, Ilya. O fim das certezas. São Paulo: UNESP, 1996.

22. ROCHA, Leonel; KÒLLING, Gabrielle; OLSSON, Gustavo. Interações entre o sistema da medicina e da saúde: observações a partir de da Teoria dos Sistemas Sociais. Sequência, Florianópolis, n. 83, p. 160-192, 2020.

23. RODRIGUES, Léo P. O Platô sistêmico na teoria social: uma revolução científica às avessas. In: Dados, v. 57, n. 4, p. 1109-1135, 2014.

24. RODRIGUES, Léo Peixoto. Da fisiologia à sociologia? Elementos para uma revisão da história teórica da sociologia sistêmica. Revista Brasileira de Ciências Sociais, v. 28, n. 82, p. 165-178, 2013. 
25. RODRIGUES, Léo P. Sistemas autorreferentes, autopoiéticos: noções-chave para a compreensão de Niklas Luhmann. Pensamento Plural, v. 3 p. 105-120, 2008.

26. RODRIGUES, Léo P.; NEVES, Fabrício M. A sociologia de Niklas Luhmann. Petrópolis: Vozes, 2017.

27. RODRIGUES, Léo P.; NEVES, Fabrício M. Niklas Luhmann: a sociedade como sistema. Porto Alegre: EDIPUCRS, 2012.

28. SCHWARTZ, Germano. A autopoiese do sistema sanitário. Revista de Direito Sanitário, São Paulo, v. 4, n. 1, p. 50-59, 2003.

29. SILVA, Marcelo José; SCHRAIBER, Lilia; MOTA, André. O conceito de saúde na Saúde Coletiva: contribuições a partir da crítica social e histórica da produção científica. Physis, v. 29, n. 1, p. 2-19 2019.

30. STICHWEH, Rudolf. El concepto de sociedad mundial. Génesis y formación de estructuras de un sistema social global. In: CADENAS, Hugo; MASCAREÑO, Aldo; URQUIZA, Anahí (eds.). Niklas Luhmann y el legado universalista de su teoría. Aportes para el análisis de la complejidad social contemporánea. Santiago: RIL Editores, 2012. p. 23-48.

31. TESINI, Brenda. Coronavírus e síndromes respiratórias agudas (Covid-19, Mers e Sars). In: Manual MSD para profissionais da saúde. 2020. Disponível em: https://www.msdmanuals.com/pt-pt/profissional/doen \%C3\%A7as-infecciosas/ v\%C3\%ADrus-respirat\%C3\%B3rios/coronav\%C3\%ADrus-e-s\%C3\%ADndromesrespirat\%C3\%B3rias-agudas-covid-19,-mers-e-sars.

32. UNESCO. COVID-19 educational disruption and response. 2020. Disponível em: https://en.unesco.org/covid19/educationresponse.

33. ZHU, Na etal. A novel coronavirus from patients with pneumonia in China, 2019. The New England Journal of Medicine, v. 382, n. 8, p. 727-733, 2020. Disponível em: https://www.nejm.org/doi/pdf/10.1056/NEJMoa2001017?articleTools=true.

Recebido em: 11 maio 2020.

Aceito em: 18 agosto 2020. 